\title{
Prevalence of Esophageal Atresia among 18 International Birth Defects Surveillance Programs
}

\author{
Natasha Nassar ${ }^{1}$, Emanuele Leoncini ${ }^{2}$, Emmanuelle Amar ${ }^{3}$, Jazmín Arteaga-Vázquez ${ }^{4}$, \\ Marian K. Bakker ${ }^{5}$, Carol Bower ${ }^{6}$, Mark A. Canfield ${ }^{7}$, Eduardo E. Castilla ${ }^{8,9,10}$, Guido \\ Cocchi $^{11}$, Adolfo Correa ${ }^{12,13}$, Melinda Csáky-Szunyogh ${ }^{14}$, Marcia L. Feldkamp ${ }^{15,16}$, Babak \\ Khoshnood $^{17}$, Danielle Landau ${ }^{18}$, Nathalie Lelong ${ }^{17}$, Jorge S. López-Camelo ${ }^{8,9}$, R. Brian \\ Lowry $^{19}$, Robert McDonnell ${ }^{20}$, Paul Merlob ${ }^{21}$, Julia Métneki ${ }^{14}$, Margery Morgan ${ }^{22}$, Osvaldo \\ M. Mutchinick ${ }^{4}$, Miland N. Palmer ${ }^{16}$, Anke Rissmann ${ }^{23}$, Csaba Siffel $^{12}$, Antonin Sipek ${ }^{24}$, \\ Elena Szabova ${ }^{25}$, David Tucker $^{22}$, and Pierpaolo Mastroiacovo ${ }^{2}$
}

${ }_{1}^{1}$ Population Perinatal Health Research, Kolling Institute of Medical Research, University of Sydney, Australia ${ }^{2}$ Center of the International Clearinghouse for Birth Defects Surveillance and Research, Rome, Italy ${ }^{3}$ Rhone-Alps Registry of Birth Defects REMERA, Lyon, France ${ }^{4}$ Instituto Nacional de Ciencias Médicas y Nutrición "Salvador Zubirán", Departamento de Genética, Registro y Vigilancia Epidemiológica de Malformaciones Congénitas, Mexico City, Mexico ${ }^{5}$ EUROCAT Northern Netherlands, Department of Genetics, University of Groningen, University Medical Center Groningen, Groningen, The Netherlands ${ }^{6}$ Western Australian Register of Developmental Anomalies, Perth, Australia ${ }^{7}$ Birth Defects Epidemiology and Surveillance Branch, Texas Department of State Health Services, Austin, Texas ${ }^{8}$ Instituto Nacional de Genética Médica Populacional, Rio de Janeiro, Brazil ${ }^{9}$ Estudio Colaborativo Latino Americano de Malformaciones Congenitas at Centro de Educación Médica e Investigación Clínica, Buenos Aires, Argentina ${ }^{10}$ Estudio Colaborativo Latino Americano de Malformaciones Congenitas at Laboratório de Epidemiologia de Malformações Congênitas, Instituto Oswaldo Cruz, Fundação Oswaldo Cruz, Rio de Janeiro, Brazil ${ }^{11}$ Indagine Malformazioni congenite Emilia Romagna Registry, Department of Pediatrics, Bologna University, Bologna, Italy ${ }^{12}$ Metropolitan Atlanta Congenital Defects Program, Division of Birth Defects and Developmental Disabilities, Centers for Disease Control and Prevention, Atlanta, Georgia ${ }^{13}$ Department of Medicine, University of Mississippi Medical Center, Jackson, Mississippi ${ }^{14}$ Department of Hungarian Congenital Abnormality Registry and Surveillance, National Center for Healthcare Audit and Inspection, Budapest, Hungary ${ }^{15}$ Division of Medical Genetics, University of Utah Health Sciences Center, Salt Lake City, Utah ${ }^{16}$ Utah Birth Defect Network, Utah Department of Health, Salt Lake City, Utah ${ }^{17}$ Institut National de la Santé et de la Recherche Médicale, Unité Mixte de Recherche S953, Epidemiological Research on Perinatal Health and Women's and Children's Health, Hôpital Cochin and UPMC University, Paris, France ${ }^{18}$ Department of Neonatology, Soroka University Medical Center, Beer-Sheba, Israel ${ }^{19}$ Alberta Congenital Anomalies Surveillance System, Alberta Health and Wellness, Calgary, Canada ${ }^{20}$ Dublin EUROCAT Registry, Health Service Executive, Dublin, Ireland ${ }^{21}$ Department of Neonatology, Rabin Medical Center, Beilinson Campus, Petah Tikva, Israel ${ }^{22}$ Congenital Anomaly Register for Wales, Singleton Hospital, Swansea, Wales, 
United Kingdom ${ }^{23}$ Malformation Monitoring Centre Saxony-Anhalt, Otto-von-Guericke University Magdeburg, Germany ${ }^{24}$ National Registry of Congenital Anomalies of the Czech Republic, Department of Medical Genetics, Thomayer University Hospital, Prague, Czech Republic

${ }^{25}$ Slovak Teratologic Information Centre, Slovak Medical University, Bratislava, Slovak Republic

\section{Abstract}

BACKGROUND-The prevalence of esophageal atresia (EA) has been shown to vary across different geographical settings. Investigation of geographical differences may provide an insight into the underlying etiology of EA.

METHODS—The study population comprised infants diagnosed with EA during 1998 to 2007 from 18 of the 46 birth defects surveillance programs, members of the International Clearinghouse for Birth Defects Surveillance and Research. Total prevalence per 10,000 births for EA was defined as the total number of cases in live births, stillbirths, and elective termination of pregnancy for fetal anomaly (ETOPFA) divided by the total number of all births in the population.

RESULTS-Among the participating programs, a total of 2943 cases of EA were diagnosed with an average prevalence of 2.44 (95\% confidence interval [CI], 2.35-2.53) per 10,000 births, ranging between 1.77 and 3.68 per 10,000 births. Of all infants diagnosed with EA, 2761 (93.8\%) were live births, 82 (2.8\%) stillbirths, 89 (3.0\%) ETOPFA, and 11 (0.4\%) had unknown outcomes. The majority of cases $(2020,68.6 \%)$, had a reported EA with fistula, $749(25.5 \%)$ were without fistula, and 174 (5.9\%) were registered with an unspecified code.

CONCLUSIONS-On average, EA affected 1 in 4099 births (95\% CI, 1 in 3954-4251 births) with prevalence varying across different geographical settings, but relatively consistent over time and comparable between surveillance programs. Findings suggest that differences in the prevalence observed among programs are likely to be attributable to variability in population ethnic compositions or issues in reporting or registration procedures of EA, rather than a real risk occurrence difference.

\section{Keywords}

esophageal atresia; congenital anomalies; prevalence; epidemiology

\section{INTRODUCTION}

Esophageal atresia (EA) is the most frequent anomaly of the esophagus and is characterized by the complete discontinuity of the esophagus with or without an abnormal connection between the esophagus and the trachea-tracheo-esophageal fistula (TEF). Diagnosis occurs prenatally or, in most cases, at birth and surgical repair is required in the first few days of life. Although the etiology of EA is largely unknown (Felix et al., 2009), geographic, temporal, and ethnic variations have been reported.

The prevalence of EA has been shown to vary across and within different geographical settings with a study from five regions in Britain reporting estimates ranging between 0.7 and 3.2 per 10,000 births (Rankin et al., 2005), although EA cases in that study also included 
those with esophageal stenosis. Similarly, differences in rates among areas in the United States have been reported with a prevalence of 2.24 in Hawaii (Forrester and Merz, 2005), 2.33 in Texas (Ethen and Canfield, 2002), and 2.82 per 10,000 births in California (Torfs et al., 1995); among European countries, prevalence has been reported for Iceland (1.83 per 10,000; Gunnarsdottir et al., 2004), Strasbourg, France (2.96 per 10,000; Stoll et al., 2009), and the United Kingdom Northern Region (3.13 per 10,000 births; Sparey et al., 2000). Given that EA is a rare condition, small numbers may also have a potential effect on rates. Ethnic composition of a population may also influence EA prevalence, with lower rates noted among Hispanic and African American communities (Carmichael et al., 2004; Forrester and Merz, 2005).

International differences in the prevalence of EA across different geographical regions may also be attributable to differences in case identification methods, case definition, and case ascertainment.

Best estimates of prevalence of major birth defects, based on international data, are important to serve as a reference point for the evaluation of individual, regional, or national surveillance programs and to identify geographical regions of higher or lower than expected prevalence (Leoncini et al., 2008; Cocchi et al., 2010). Investigation of geographical differences may also provide an insight into the underlying etiology of EA. The aim of this study was to investigate the international prevalence of EA among birth defects surveillance programs in North and South America, Europe, and Australia and provide a worldwide collective estimate.

\section{MATERIALS AND METHODS}

Data for this study were sourced from 18 birth defects surveillance programs, all members of the International Clearinghouse for Birth Defects Surveillance and Research (ICBDSR). Programs who agreed to participate provided relevant data on EA among live births, stillbirths, and elective termination of pregnancy for fetal anomaly (ETOPFA), if permitted. All participating programs were also required to have a stable methodology of ascertainment and registration over the 10-year study period of 1998 to 2007. The following programs provided data for slightly different years: Slovak Republic, 2001 to 2007; Texas, 1997 to 2006; and Utah, 1999 to 2007.

The main characteristics of the 18 participating programs in this study are reported in Table 1, with additional details available from the annual reports of the ICBDSR (http:// www.icbdsr.org; International Clearing-house for Birth Defects Surveillance and Research, 2008) and the National Birth Defects Prevention Network (http://www.nbdpn.org; National Birth Defects Prevention Network, 2008), and from selected publications from individual programs (Mutchinick et al., 1988; Czeizel, 1997; Correa-Villasenor et al., 2003; Castilla and Orioli, 2004; De Vigan et al., 2005; Feldkamp et al., 2005; Bower et al., 2009; Lowry RB et al., 2009).

Classification of cases was undertaken by each individual program using either the British Pediatric Association International Classification of Diseases (ICD) coding system (ICD9- 
BPA) or ICD10. For this study, EA cases included all reported infants and fetuses diagnosed with an esophageal atresia with TEF (ICD9-BPA: 750.31, 750.33; ICD10: Q39.1) or without TEF (ICD9-BPA: 750.30; ICD10: Q39.0) or unspecified EA (750.3). Other types of EA including TEF without atresia (ICD9-BPA: 750.32; ICD10: Q39.2), esophageal stenosis, or esophageal web (ICD9-BPA: 750.34, 750.35; ICD10: Q39.3, Q39.4) were considered separately.

Total prevalence per 10,000 births was defined as the total number of cases among live births, stillbirths, and ETOPFA divided by the total number of all births (live births and stillbirths) in the population. Spontaneous abortions were not considered. We used the term total prevalence instead of prevalence or birth prevalence to underline that ETOPFA was also included. To validate the total prevalence, we undertook a sensitivity analysis by comparing overall total prevalence to estimated result for six programs previously shown to have good ascertainment of birth defects (Leoncini et al., 2010). Ninety-five percent confidence intervals (CIs) for prevalence were calculated based on the Poisson distribution. Chi-square test for trend was used to evaluate homogeneity and time trend of the prevalence in the study period. Statistical analyses were performed using Stata 9.0 (Stata Corporation, College Station, TX) and SAS 9.1 (SAS Institute, Cary, NC), with $p<0.05$ considered statistically significant.

\section{RESULTS}

Among the eighteen surveillance programs of the ICBDSR, a total of 2943 cases of EA were registered between 1998 and 2007 (Table 2). The majority of cases (2020,68.6\%) had a reported esophageal atresia with fistula, 749 cases (25.5\%) were without fistula, and 174 cases $(5.9 \%)$ were unspecified. The total prevalence of EA was 2.44 (95\% CI, 2.35-2.53) per 10,000 births; and on average, EA affected 1 in 4099 births (95\% CI, 3954-4251 births). The prevalence ranged from 1.77 (95\% CI, 1.52-2.06) per 10,000 births in Hungary and Atlanta to 3.68 (95\% CI, 3.41-3.97) in South America (Table 2). Sensitivity analysis using data from programs with optimal ascertainment of cases revealed that total prevalence of EA was 2.47 per 10,000 births.

Overall, the average annual trend in EA remained fairly constant over the study period varying between 2.32 in 1998 to 2.60 per 10,000 births in 2007, and there was no evidence of a significant linear trend in EA among each of the programs (data not shown). However, there was a modest decline in the trend of EA in Alberta and Dublin, and a slight increase in cases in Western Australia, Mexico, and Israel.

Of all infants with a diagnosis of EA, there were 2761 (93.8\%) live births, 82 (2.8\%) stillbirths, 89 (3.0\%) ETOP-FAs, and $11(0.4 \%)$ with unspecified outcome. Programs in Dublin and Alberta had a relatively higher proportion of stillbirths (14.0\% and $11.4 \%$, respectively); in the case of ETOPFA, two programs (i.e., Central East, France and Wales) reported one in five cases that resulted in a termination of pregnancy (Fig. 1). Excluding ETOPFA, the total prevalence of EA reduced slightly to 2.37 (95\% CI, 2.28-2.45) per 10,000 births. 
The total prevalence of TEF without atresia was 0.22 per 10,000 births (95\% CI, 0.19-0.24; 1 in every 46,398 births). Compared with EA, TEF without atresia was reported much less frequently $(<0.5$ per 10,000 births) by all members of ICBDSR except for Western Australia, where the prevalence was 1.3 per 10,000 births. Cases of esophageal stenosis or esophageal web $(n=44)$ occurred rarely, 1 in every 274,170 births ( 0.04 per 10,000 births), but was more commonly diagnosed in Saxony-Anhalt, Germany ( 0.12 per 10,000 births) compared with all other surveillance programs.

\section{DISCUSSION}

Esophageal atresia affects an average of 1 in every 4099 births, with a total prevalence of 2.44 (95\% CI, 2.35-2.53) per 10,000 births among 18 birth defects surveillance program members of the ICBDSR. The prevalence ranged between 1.77 and 3.68 per 10,000 births among members representing North and South America, Europe, and Australia. However, sensitivity analysis limiting data to member programs with optimal case ascertainment revealed an almost identical total prevalence (2.47). The findings are also similar to an earlier study of EA among nine ICBDSR programs reporting a prevalence of $2.56 \mathrm{per}$ 10,000 births from 1965 to 1989 (Robert et al., 1993).

Findings from other congenital anomaly surveillance programs such as EUROCAT (the European surveillance of congenital anomalies working group) reported a comparable prevalence of 2.46 per 10,000 births among 23 member registries for the years 1997 to 2006 (Pedersen et al., 2012). This analysis included five ICBDSR members from our present study. When limiting our data to 10 European members of the ICBDSR, we also found the same result (2.44 per 10,000 births). The estimated national prevalence of EA reported by the U.S. National Birth Defects Prevention Network was 2.12 per 10,000 births (adjusted for race or ethnicity) among 14 member programs for the period from 2004 to 2006. Slight differences in prevalence by case ascertainment methods were observed with results ranging from 2.17 among 10 programs using active birth defects surveillance to 2.36 among seven passive surveillance systems and 2.54 among five passive surveillance programs with a case confirmation component (Parker et al., 2010).

Despite the range of geographic locations and study periods, comparison of the total prevalence of EA by various international surveillance programs reveals relatively similar results with EA diagnosed among 1 in 4099 to 4608 infants. These findings highlight the relative stability of the prevalence of EA, internationally and over time. In our international study, there was no consistent trend for neighboring countries or states within continents, with a small variability in prevalence potentially influenced by chance or differences in reporting or surveillance methods, study population, ethnic distribution, or geographical or environmental factors. For example, the two programs reporting higher prevalence of EA (South America and Israel) may be explained by their hospital-based case ascertainment program with active notification by trained clinicians in each hospital. However, higher prevalence may also reflect a truly higher rate of EA, and further investigation of these results is important. Conversely, slightly lower prevalence of EA reported from surveillance programs in Atlanta and Texas may be explained by the ethnic composition of the population in these two U.S. states, with almost two thirds of all infants born to African 
American or Hispanic women, respectively (National Birth Defects Prevention Network, 2009). Studies of congenital malformations by ethnic groups in the United States have found that compared with non-Hispanic white women, Hispanic and African American women had a reduced risk of EA without fistula (relative risk, 0.75; 95\% CI, 0.62-0.90; and relative risk, 0.59; 95\% CI, 0.62-0.90; respectively; Carmichael et al., 2004; Forrester and Merz, 2005). In Hungary, a combination of incomplete registration of cases at birth and terminations of pregnancy, and a true lower prevalence may explain their lower estimates.

Although there was some discrepancy among programs in the distribution of specific types of EA (with and without TEF), the overall proportions were similar to those reported in the literature (Clark, 1999; Shaw-Smith, 2006; Spitz, 2007). These differences may be due to variation in classification, identification, or reporting practices across programs rather than reflect real differences (Shaw-Smith, 2006; Spitz, 2007). Higher prevalence of TEF without atresia in some settings may also be due to increased detection and sources of notification such as post mortem evaluation (Bower et al., 2009). Several factors may also influence reporting and registration of EA including: screening policies and procedures, clinician skills, timing of aneuploidy and fetal anomaly screening, subsequent availability and timing of elective termination of pregnancy, and autopsy policies. Previous studies have shown that the rate of termination of pregnancy is higher for cases with chromosomal or additional congenital anomalies than for cases with an isolated anomaly (Haeusler et al., 2002; Garne et al., 2007). Chromosomal anomalies have been reported to occur in 6 to $10 \%$ of EA cases (Garne et al., 2007; Genevieve et al., 2007; Pedersen et al., 2012); while greater than 50\% and up to two thirds of infants with EA have additional anomalies (Genevieve et al., 2007; Spitz, 2007; de Jong et al., 2010a; Pedersen et al., 2012). Given that EA is more likely to be diagnosed in conjunction with other syndromes (particularly VACTERL: Vertebral anomalies, Anal atresia, Cardiovascular anomalies, Tracheo-Esophageal fistula, Renal and/or Radial anomalies, Limb defects) or chromosomal anomalies that may result in termination of pregnancy, it is important to include terminated cases in ascertainment (Shaw-Smith, 2006; Felix et al., 2009). For some anomalies, availability and reporting of ETOPFA may increase ascertainment of cases. In this study, total prevalence of EA was only slightly attenuated to 2.37 per 10,000 births if terminations were excluded. This finding was confirmed by a study from Texas that found no effect on estimates of EA when elective terminations before 20 weeks' gestation were included in case ascertainment (Ethen and Canfield, 2002).

The underlying etiology of EA has been described as multifactorial and is likely to differ across settings (Robert et al., 1993; Felix et al., 2009; de Jong et al., 2010b). In addition to maternal ethnicity and geographic location, previous studies have reported EA to be associated with maternal age (Leck et al., 1968; Harris et al., 1995), multiple gestation (Harris et al., 1995; Riley et al., 1998), infant sex (Robert et al., 1993) and use of assisted reproductive technology (Reefhuis et al., 2009). In a recent study of EA in the United States, women using assisted reproductive technology had a 4.5 -fold increased risk of having an infant with EA (Reefhuis et al., 2009). Prevalence of EA has also been found to be higher among multiple births compared with singletons (Harris et al., 1995; Riley et al., 1998), and increased risk was reported with increasing maternal age (Leck et al., 1968; Harris et al., 1995). In contrast, a protective effect was found among women who have had three or more 
births (OR, 0.50; 95\% CI, 0.36-0.71; Harris et al., 1995; Carmichael et al., 2004). However, given the low frequency of occurrence of most of these factors in the general population, the population-attributable risk is likely to be minimal. Variations in ethnicity as detailed above may also be surrogates for a number of different exposures, including socioeconomic status, nutrition, stress, and access to services. Differences in lifestyle factors, such as smoking or dietary habits within countries or regional variation, may also affect estimates. However, lack of temporal trends among the included programs suggests environmental factors, which change over time, are less likely to play a role in the development of EA (Robert et al., 1993; Canfield et al., 2006; Garne et al., 2007). Underlying and still unknown (Genevieve et al., 2011) genetic susceptibility, biologic or physical differences may also modify risk of exposures. Although a number of genetic abnormalities have been associated with EA, no specific gene has been implicated (Felix et al., 2009). Further study with more detailed information to assess risk factors and underlying characteristics of cases with EA is required.

One of the limitations of the study is that it did not collect information on maternal risk factors that might help to elucidate the etiology of EA or explain differences in the prevalence across settings. Furthermore, we did not collect information to differentiate between isolated cases and those with associated (multiple) or chromosomal anomalies because of difficulties in standardizing the definition of associated anomalies across programs. Despite these limitations, one of the strengths of the study is that case identification is likely to be complete because EA is diagnosable either antenatally or at the time of birth and require surgical attention. Recent studies from the Netherlands and Oxford, U.K., reported that diagnosis of EA occurred prenatally in 38\% of infants (Choudhry et al., 2007; Garne et al., 2007; de Jong et al., 2010a; Pedersen et al., 2012). Postnatally, EAs are suspected and diagnosed by respiratory or feeding difficulties and inability to pass a nasogastric tube; they are confirmed on chest radiograph with surgical correction within 24 to 48 hours (Spitz, 2007).

In conclusion, EA affects an average of 1 in every 4099 births worldwide and has remained surprisingly stable over time. Although there was some variation in the reported prevalence among and within countries, overall EA was also relatively consistent across European and American surveillance programs. Findings suggest that differences in the prevalences observed among programs are likely to be attributable to local phenomena affecting reporting or case registration of EA or ethnic composition, rather than a real difference in risk occurrence per se. Future epidemiologic studies accounting for ethnic distribution, maternal characteristics, genetic factors, and associated anomalies may provide important information regarding the underlying epidemiology of EA.

\section{Acknowledgments}

Supported by the Centers for Disease Control and Prevention (CDC), National Center on Birth Defects and Developmental Disabilities (Project Collaborative International Birth Defects Surveillance and Program, grant no. 1U50DD000524-01). Natasha Nassar is supported by an Australian National Health and Medical Research Council Career Development Fellowship (no. 632955).

We thank Simonetta Zezza for the formatting the manuscript and liaising with contributing members, and Eva Veghova and Daniela Bras enova for their skillful support. 


\section{References}

Bower, C.; Rudy, E.; Callaghan, A., et al. Report of the Birth Defects Registry Of Western Australia, 1980-2008. Perth: King Edward Memorial Hospital; 2009. Available at: http:// kemh.health.wa.gov.au/services/register_developmental_anomalies/documents/ 2009_Annual_Report.pdf [Accessed August 9, 2012]

Canfield MA, Ramadhani TA, Yuskiv N, et al. Improved national prevalence estimates for 18 selected major birth defects-United States, 1999-2001. MMWR Morb Mortal Wkly Rep. 2006; 54:13011305. [PubMed: 16397457]

Carmichael SL, Shaw GM, Kaidarova Z, et al. Congenital malformations in offspring of Hispanic and African-American women in California, 1989-1997. Birth Defects Res A Clin Mol Teratol. 2004; 70:382-388. [PubMed: 15211706]

Castilla EE, Orioli IM. ECLAMC: the Latin-American collaborative study of congenital malformations. Community Genet. 2004; 7:76-94. [PubMed: 15539822]

Choudhry M, Boyd PA, Chamberlain PF, et al. Prenatal diagnosis of tracheo-oesophageal fistula and oesophageal atresia. Prenat Diagn. 2007; 27:608-610. [PubMed: 17457956]

Clark DC. Esophageal atresia and tracheoesophageal fistula. Am Fam Physician. 1999; 59:910-916. 919-920. [PubMed: 10068713]

Cocchi G, Gualdi S, Bower C, et al. International trends of Down syndrome 1993-2004: Births in relation to maternal age and terminations of pregnancies. Birth Defects Res A Clin Mol Teratol. 2010; 88:474-479. [PubMed: 20589916]

Correa-Villasenor A, Cragan J, Kucik J, et al. The Metropolitan Atlanta Congenital Defects Program: 35 years of birth defects surveillance at the Centers for Disease Control and Prevention. Birth Defects Res A Clin Mol Teratol. 2003; 67:617-624. [PubMed: 14703783]

Czeizel AE. First 25 years of the Hungarian congenital abnormality registry. Teratology. 1997; 55:299-305. [PubMed: 9261923]

de Jong EM, de Haan MA, Gischler SJ, et al. Pre- and postnatal diagnosis and outcome of fetuses and neonates with esophageal atresia and tracheoesophageal fistula. Prenat Diagn. 2010a; 30:274-279. [PubMed: 20112230]

de Jong EM, Felix JF, de Klein A, et al. Etiology of esophageal atresia and tracheoesophageal fistula: "mind the gap. Curr Gastroenterol Rep. 2010b; 12:215-222. [PubMed: 20425471]

De Vigan C, Khoshnood B, Lhomme A, et al. Prevalence and prenatal diagnosis of congenital malformations in the Parisian population: twenty years of surveillance by the Paris Registry of congenital malformations. J Gynecol Obstet Biol Reprod (Paris). 2005; 34:8-16. [PubMed: 15767912]

Ethen MK, Canfield MA. Impact of including elective pregnancy terminations before 20 weeks gestation on birth defect rates. Teratology. 2002; 66(Suppl 1):S32-35. [PubMed: 12239742]

Feldkamp M, Macleod L, Young L, et al. The methodology of the Utah Birth Defect Network: congenital heart defects as an illustration. Birth Defects Res A Clin Mol Teratol. 2005; 73:693699. [PubMed: 16240379]

Felix JF, de Jong EM, Torfs CP, et al. Genetic and environmental factors in the etiology of esophageal atresia and/or tracheoesophageal fistula: an overview of the current concepts. Birth Defects Res A Clin Mol Teratol. 2009; 85:747-754. [PubMed: 19452513]

Forrester MB, Merz RD. Epidemiology of oesophageal atresia and tracheo-oesophageal fistula in Hawaii, 1986-2000. Public Health. 2005; 119:483-488. [PubMed: 15826889]

Garne E, Loane M, Dolk H, et al. Gastrointestinal malformations: impact of prenatal diagnosis on gestational age at birth. Paediatr Perinat Epidemiol. 2007; 21:370-375. [PubMed: 17564595]

Genevieve D, de Pontual L, Amiel J, et al. An overview of isolated and syndromic oesophageal atresia. Clin Genet. 2007; 71:392-399. [PubMed: 17489843]

Genevieve D, de Pontual L, Amiel J, et al. Genetic factors in isolated and syndromic esophageal atresia. J Pediatr Gastroenterol Nutr. 2011; 52(Suppl 1):S6-8. [PubMed: 21499049]

Gunnarsdottir A, Bjarnason G, Haraldsson A, et al. Oesophageal atresia in Iceland 1963-2002; Incidence outcome. Laeknabladid. 2004; 90:629-633. [PubMed: 16819050] 
Haeusler MC, Berghold A, Stoll C, et al. Prenatal ultrasonographic detection of gastrointestinal obstruction: results from 18 European congenital anomaly registries. Prenat Diagn. 2002; 22:616623. [PubMed: 12124699]

Harris J, Kallen B, Robert E, et al. Descriptive epidemiology of alimentary tract atresia. Teratology. 1995; 52:15-29. [PubMed: 8533109]

International Clearinghouse for Birth Defects Surveillance and Research. Annual Report 2008. Rome: International Clearinghouse for Birth Defects Surveillance and Research Centre; 2008.

Leck I, Record RG, McKeown T, et al. The incidence of malformations in Birmingham, England, 1950-1959. Teratology. 1968; 1:263-280. [PubMed: 5759547]

Leoncini E, Baranello G, Orioli IM, et al. Frequency of holoprosencephaly in the International Clearinghouse Birth Defects Surveillance Systems: searching for population variations. Birth Defects Res A Clin Mol Teratol. 2008; 82:585-591. [PubMed: 18566978]

Leoncini E, Botto LD, Cocchi G, et al. How valid are the rates of Down syndrome internationally? Findings from the International Clearinghouse for Birth Defects Surveillance and Research. Am J Med Genet A. 2010; 152A:1670-1680. [PubMed: 20578135]

Lowry, RB.; Sibbald, B.; Wang, FL. Congenital Anomalies Surveillance System: Seventh Report, 1980-2005. Edmonton, AB: Alberta Health and Wellness; 2009. Alberta Health and Wellness. 2007.

Mutchinick O, Lisker R, Babinski V, et al. The Mexican program of Registration and Epidemiologic Surveillance of External Congenital Malformations. Salud Publica Mex. 1988; 30:88-100. [PubMed: 3358211]

National Birth Defects Prevention Network. State Birth Defects Surveillance Program Directory. Birth Defects Res A Clin Mol Teratol. 2008; 82:906-961.

National Birth Defects Prevention Network. Population-based Birth Defects Surveillance data from selected states, 2002-2006. Birth Defects Res A Clin Mol Teratol. 2009; 85:939-1055. [PubMed: 19998459]

Parker SE, Mai CT, Canfield MA, et al. Updated National Birth Prevalence estimates for selected birth defects in the United States, 2004-2006. Birth Defects Res A Clin Mol Teratol. 2010; 88:10081016. [PubMed: 20878909]

Pedersen RN, Calzolari E, Husby S, Garne E. EUROCAT Working Group. Oesophageal atresia: prevalence, prenatal diagnosis and associated anomalies in 23 European regions. Arch Dis Child. 2012; 97:227-232. [PubMed: 22247246]

Rankin J, Pattenden S, Abramsky L, et al. Prevalence of congenital anomalies in five British regions, 1991-99. Arch Dis Child Fetal Neonatal Ed. 2005; 90:F374-379. [PubMed: 16113153]

Reefhuis J, Honein MA, Schieve LA, et al. Assisted reproductive technology and major structural birth defects in the United States. Hum Reprod. 2009; 24:360-366. [PubMed: 19010807]

Riley MM, Halliday JL, Lumley JM, et al. Congenital malformations in Victoria, Australia, 1983-95: an overview of infant characteristics. J Paediatr Child Health. 1998; 34:233-240. [PubMed: 9633969]

Robert E, Mutchinick O, Mastroiacovo P, et al. An international collaborative study of the epidemiology of esophageal atresia or stenosis. Reprod Toxicol. 1993; 7:405-421. [PubMed: 8274816]

Shaw-Smith C. Oesophageal atresia, tracheo-oesophageal fistula, and the VACTERL association: review of genetics and epidemiology. J Med Genet. 2006; 43:545-554. [PubMed: 16299066]

Sparey C, Jawaheer G, Barrett AM, et al. Esophageal atresia in the Northern Region Congenital Anomaly Survey, 1985-1997: prenatal diagnosis and outcome. Am J Obstet Gynecol. 2000; 182:427-431. [PubMed: 10694347]

Spitz L. Oesophageal atresia. Orphanet J Rare Dis. 2007; 2:24. [PubMed: 17498283]

Stoll C, Alembik Y, Dott B, et al. Associated malformations in patients with esophageal atresia. Eur J Med Genet. 2009; 52:287-290. [PubMed: 19410022]

Torfs CP, Curry CJ, Bateson TF, et al. Population-based study of tracheoesophageal fistula and esophageal atresia. Teratology. 1995; 52:220-232. [PubMed: 8838292] 


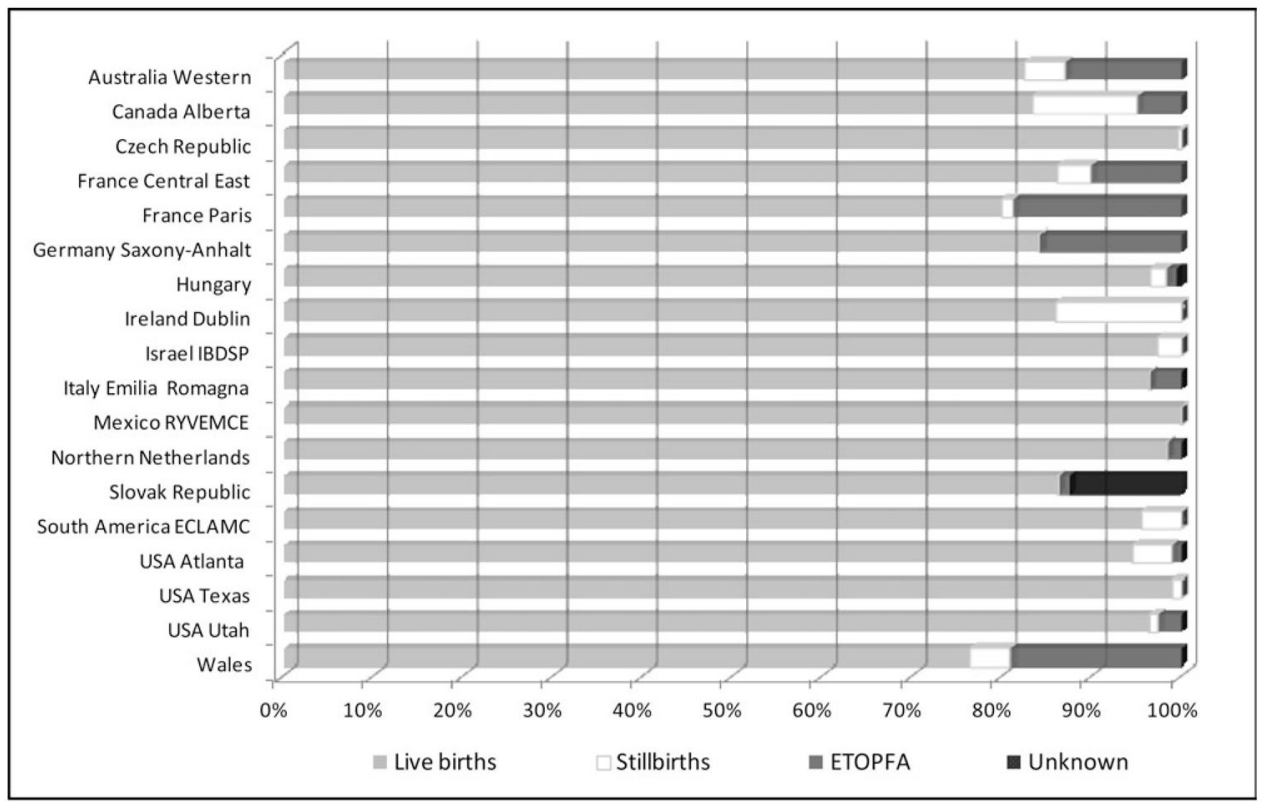

ETOPFA = elective termination of pregnancy for fetal anomaly

Figure 1.

Proportion of esophageal atresia among eighteen surveillance program members of the International Clearinghouse for Birth Defects Surveillance and Research, by pregnancy outcome, 1998-2007. 
Nassar et al.

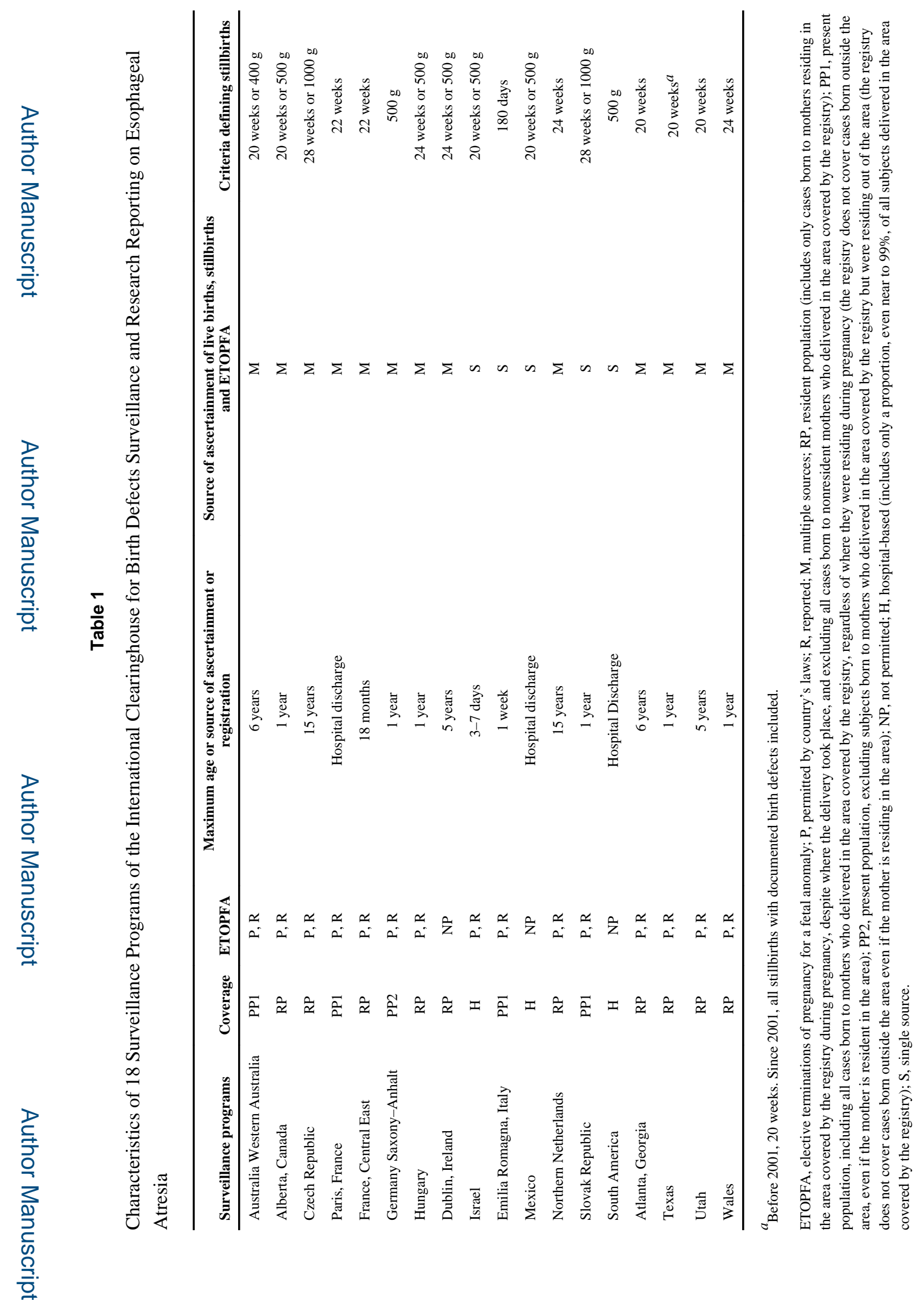

Birth Defects Res A Clin Mol Teratol. Author manuscript; available in PMC 2015 June 15. 


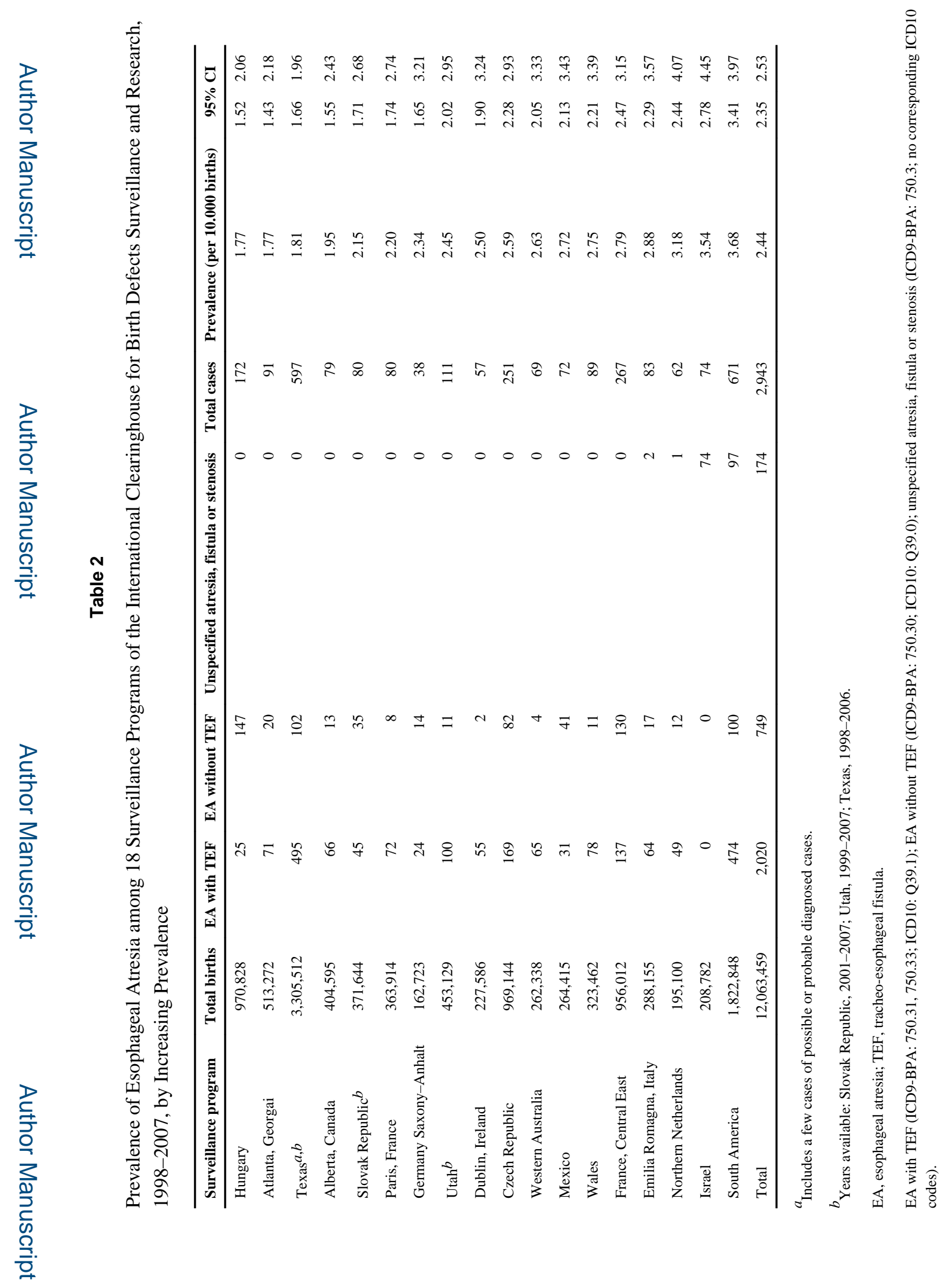

Birth Defects Res A Clin Mol Teratol. Author manuscript; available in PMC 2015 June 15. 